\title{
Cellular and molecular mechanisms in COVID-19 coagulopathy: role of inflammation and endotheliopathy
}

\author{
Rossella Cacciola ${ }^{1}\left[\right.$ Elio Gentilini Cacciola ${ }^{2} \cdot$ Veronica Vecchio $^{3} \cdot$ Emma Cacciola $^{4}(\mathbb{0}$ \\ Accepted: 3 October 2021 / Published online: 23 October 2021 \\ (c) The Author(s), under exclusive licence to Springer Science+Business Media, LLC, part of Springer Nature 2021
}

\begin{abstract}
Introduction Coronavirus 2 (CoV-2) infection or coronavirus disease 2019 (COVID-19) is frequently associated with microvascular thrombosis. The microthrombosis in COVID-19 is the result of the interplay between inflammation and endotheliopathy. Elevated interleukin-6 (IL-6) characterizes COVID-19 inflammation resulting in endotheliopathy and coagulopathy marked by elevated D-dimer (DD). Aim of this study is to identify and to describe the coagulation changes in 100 moderate COVID-19 patients having lung involvement and to determine the association of coagulopathy with the severity and prognosis.

Methods Inflammation, endothelial and coagulation molecules were measured in moderate and mild disease.

Results IL-6 and tumor necrosis factor- $\alpha$ (TNF- $\alpha$ ) and tissue factor (TF), von Willebrand factor (VWF), and tissue factor pathway inhibitor (TFPI) significantly increased in moderate disease as well as D-dimer, thrombin antithrombin complex (TAT), Fibrinogen (Fib), platelet factor-4 (PF4), $\beta$-thromboglobulin ( $\beta$-TG), P-selectin, and platelet adhesion. Shortened clotting time (CT) and clot formation time (CFT), high maximum clot firmness (MCF) and low LY at 30 min were present in $100 \%$ of moderate COVID-19 patients compared with mild COVID-19 patients.

Conclusions These findings demonstrate that moderate COVID-19 has a profound inflammation associated with severee ndotheliopathy and intense coagulation activation uncontrolled by TFPI.

Attention should be paid to coagulopathy in COVID-19. Closely monitoring of coagulation and application of appropriate anticoagulation may improve the prognosis of moderate COVID-19 and to prevent the progression to severe COVID-19 disease.
\end{abstract}

Keywords Cytokines $\cdot$ Endothelial molecules $\cdot$ Coagulative molecules $\cdot$ Platelet activity

\section{Highlights}

Rossella Cacciola

rcacciol@unict.it

1 Hemostasis Unit, Department of Clinical and Experimental Medicine, University of Catania, Via S. Sofia 78, 95123 Catania, Italy

2 Infectious Diseases Unit, Sapienza University of Rome, Rome, Italy

3 Medical School of Catania, University of Catania, Catania, Italy

4 Hemostasis Unit, Department of Medical, Surgical Sciences and Advanced Technologies "G.F. Ingrassia", University of Catania, Catania, Italy
- Inflammation and endotheliopathy characterize the vascular disease.

- Coagulopathy and piastrinopathy characterize the haemostasis vascular.

- Hypofibrinolysis characterizes the vascular thrombosis.

- TFPI is a prognostic marker of severe vascular disease.

\section{Introduction}

The hypercoagulability characterizes COVID-19 [1, 2]. Postmortem thrombotic microangiopathy, pulmonary thrombi and multiorgan failure have been observed [3-8]. 
Inflammation and vascular damage cause thrombi [4]. D-dimer (DD), von Willebrand antigen and PF4 are elevated in COVID-19 and DD correlates with PF4 and monocyte TF predicting mortality [9-13]. Pathogens-derived polyphosphates stimulate inflammation and monocytes and macrophages TF realizing thromboinflammation [14-20].

TF is normally present in the circulation at very low levels and its increase causes coagulation activation and thrombin generation inducing leukocyte, platelet and endothelial activation amplifying TF expression, cytokines release and inflammation [21-28]. IL-6 induces platelet reactivity and high Fib linking inflammation and thrombosis [29, 30]. Activated protein C (APC), thrombomodulin (TM) and TFPI, a endogenous serine protease producted by the endothelium, can limit microthrombosis, inflammation and organ injury [30-36]. The mechanisms underlying coagulation changes in COVID-19 are linked to inflammation [14]. It has been reported profound inflammation ("cytokine storm") characterized by high levels of inteleukin-1 (IL-1), IL-6, and TNF- $\alpha[14,37]$. The International Society of Thrombosis and Hemostasis (ISTH) developed criteria of coagulopathy called disseminated intravascular coagulopathy (DIC) and sepsisinduced coagulopathy (SIC) where SIC is a coagulopathy less severe than DIC but progressing to DIC [14, 38-40], ISTH DIC and SIC have been used in China to study the COVID-19 coagulation changes and it has been observed that COVID-19 coagulopathy is a SIC without bleeding [14, 41-44].

The link between CoV-2 and endothelial ACE-2 receptor causes death of endothelial cells, distruption of the antithrombotic properties, and thrombotic microangiopathy [14, 20, 45-47]. Therefore, an endotheliopathy contributes to the coagulation changes in COVID-19 causing micro- and macrovascular thrombosis [47-49].

Tang et al. [11] and Ranucci et al. [50] reported high Fib associated with high IL-6 confirming the interplay between inflammation and coagulation.

We investigated biomarkers and measures that have been published previously as representing risk predictors in severe COVID-19. This study differs for having studied these biomarkers and measures in moderate COVID-19.

Moderate COVID-19 exhibits increased inflammation including IL- 6 and TNF- $\alpha$ and endotheliopathy including TF, VWF and TFPI and that profound inflammation and endothelial activation are determinant to coagulation activation and platelet activation through mechanisms involving D-dimer, TAT, and Fib and PF4 and $\beta$-TG, and P-selectin, respectively. Our data shed new light on pathogenesis of the COVID-19 coagulopathy involving whole haemostatic system as documented by blood viscoelastic properties measurement. Of note that the associations observed between inflammation, endothelium, coagulation and platelet correlated with pulmonary embolism suggest a biologically plausible hypothesis.
There is no scientific basis to conclude that TFPI is responsible for worse outcome in moderate COVID-19 but the finding that TFPI does not attenuate the coagulopathy is a biologically plausible basis and the association between TFPI and dilute Prothrombin time (dPT) is a proper focus.

\section{Materials and methods}

We prospectively studied 100 moderate COVID-19 patients on reverse transcription polymerase chain reaction (RT-PCR) within $72 \mathrm{~h}$ of hospitalization. The comparator groups were 16 presenting mild disease and 16 asymptomatic patients and 40 healthy subjects age- and sex-matched SARS-CoV- $2^{-}$on RT-PCR (Table 1). The definition of moderate and mild was chosen in according to the diagnosis and treatment protocol novel coronavirus pneumonia (trial version 7) [1,51] published by the National Health Commission that has defined moderate cases showing fever and respiratory symtoms with radiological findings of pneumonia and mild cases showing mild clinical symptoms and no sign of pneumonia on imaging. The outcome of moderate cases was characterized by deterioration of disease defined as pulmonary embolism (PE) on computed tomography (CT) angiography, without mortality.Our management protocol included antithrombotic prophylaxis with 40-60 mg of enoxaparin per day and antimicrobial treatment (amoxifloxacin and/or cephalosporin) and antiviral therapy (oseltamivir and/or ganciclovir). In addition, all moderate cases were administered corticosteroid (methylprednisolone) during the course of hospitalization. The controls were not under anti-inflammatory or antiplatelet drugs for at least 2 weeks.

The justification of many biomarkers studied in this study is to have collected all the biomarkers at the time investigated in COVID-19.

\section{Inflammatory and endothelial mediators}

Interleukin-6 (IL-6) and TNF- $\alpha$ were measured by multiplex bead array (Millipore Sigma) on Luminex 200 machine, and TF, VWF and TFPI were measured by ELISA kits (R\&D Systems; Abcam and American Diagnostica Inc., Greenwich, CT).

\section{Coagulation activation mediators}

DD and TAT were measured by ELISA kit (Diagnostic Stago, Boehringer Mannheim, Mannheim, Germany; Dade Berhing Marburg GmbH, Marburg, Germany), and Fib was measured by Clauss method (Giesse Diagnostics, Italy). 
Table 1 Characteristics of COVID-19 patients and control subjects

\begin{tabular}{llll}
\hline & Controls, $\mathrm{n}=40$ & $\begin{array}{l}\text { Mild/asymptomatic, } \\
\mathrm{n}=32\end{array}$ & Moderate, $\mathrm{n}=100$ \\
\hline Age, y & $50(30-60)$ & $30(32-34)$ & $55(45-63)$ \\
Sex, male & $25(62.5)$ & $18(56.2)$ & $60(60)$ \\
Respiratory support & & & \\
Oxygen supplementation & $0(0)$ & $0(0)$ & $100(100)$ \\
Mechanical ventilation & $0(0)$ & $0(0)$ & $0(0)$ \\
28/day mortality & & $0(0)$ & $0(0)$ \\
Comorbidities & & & \\
Obesity & $0(0)$ & $0(0)$ & $0(0)$ \\
Hypertension & $0(0)$ & $0(0)$ & $0(0)$ \\
Diabetes & $0(0)$ & $0(0)$ & $0(0)$ \\
Cancer & $0(0)$ & $0(0)$ & $0(0)$ \\
Heart disease* & $0(0)$ & $0(0)$ & $92(92)$ \\
Presenting symptoms & & & $80(80)$ \\
Cough & $0(0)$ & $8(25)$ & $92(92)$ \\
Fever & $0(0)$ & $0(0)$ & $0(0)$ \\
Dyspnea & $0(0)$ & $8(25)$ & $0(0)$ \\
Headache & $0(0)$ & $5(15.6)$ & $0(0)$ \\
Anosmia & $0(0)$ & & \\
\hline & & &
\end{tabular}

\section{Platelet activation mediators}

The rational for chosen the method of released platelet materials PF4 and $\beta$-TG by ELISA kit (R\&D Systems) was the study of platelet activation function. In addition, was measured sP-Selectin by ELISA kit (R\&D Systems).

\section{Platelet adhesion}

The rational for chosen the method PFA-100 System (Dade International Inc. FL, USA-American Diagnostica Inc., Greenwich, CT Systems) using Collagen/ADP (CT-ADP) and Collagen/Epinephrine (CT-EPI) cartridges was the study of vascular platelet function.

\section{Blood viscoelastic analysis}

The whole blood hemostatic activation was measured by Thromboelastometry method (Rotem delta System-Pentapharm $\mathrm{GmbH}$, Germany) by parameters including CT describing the phase of coagulation extrinsic or intrinsic pathway activation, CFT describing the next phase of stable clot formation depending by activated platelets and fibrinogen, and MCF describing the firmness of the clot depending by activated platelets and fibrinogen, and clot lysis at $30 \mathrm{~min}$ (LY-30) describing the degree of fibrinolysis which taken place until $30 \mathrm{~min}$ after CT.

\section{Coagulation functional assays}

Citrated blood was analysed after centrifugation at $3000 \mathrm{~g}$ for $15 \mathrm{~min}$ at $18{ }^{\circ} \mathrm{C}$ on automated coagulation analyser (ACL 7000 - Instrumentation Laboratory) to measure dPT.

\section{Statistical analysis}

The results were given as the mean \pm standard deviation using the Student's t-test and correlation coefficients using the Pearson test for parametric distributions or the Spearman test for nonparametric distributions and the Fisher exact test. A p-value of $<0.05$ was considered statistically significant. The log transformation was applied to the measures prior to analysis because the measures were not distributed normally. Data were analyzed using SPSS 21.0 for Windows (SPSS Inc.)

\section{Results}

\section{The inflammation of moderate COVID-19 contributes to endothelial activation}

IL-6, TNF- $\alpha$, and TF and VWF were increased in moderate COVID-19 $(54 \pm 12 \mathrm{pg} / \mathrm{ml}, 45 \pm 5 \mathrm{pg} / \mathrm{ml}, 2000 \pm 500 \mathrm{pg} / \mathrm{ml}$ and $300 \pm 50 \%$ ) compared with mild/asymptomatic COVID$19(4 \pm 2 \mathrm{pg} / \mathrm{ml}, 9 \pm 1 \mathrm{pg} / \mathrm{ml}, 20 \pm 2 \mathrm{pg} / \mathrm{ml}$ and $40 \pm 8 \%)$ and controls $(5 \pm 2 \mathrm{pg} / \mathrm{ml}, 10 \pm 3 \mathrm{pg} / \mathrm{ml}, 23 \pm 5 \mathrm{pg} / \mathrm{ml}$ and 
$60 \pm 10 \%)$. IL-6 and TNF- $\alpha$ correlated with TF and VWF in the moderate COVID group (Table 3 ). TFPI was increased in moderate COVID-19 $(166 \pm 69 \mathrm{ng} / \mathrm{ml})$ compared to mild/ asymptomaticCOVID-19 (70 $\pm 10 \mathrm{ng} / \mathrm{ml})$ and controls $(81 \pm 12 \mathrm{ng} / \mathrm{ml})$ and correlated with inflammatory markers in the moderate COVID group (Table 3).

\section{The endotheliopathy of moderate COVID-19 contributes to coagulation activation}

DD, TAT and Fib were increased in moderate COVID-19 $(550 \pm 100 \mu \mathrm{g} / \mathrm{l}, 70 \pm 10 \mu \mathrm{g} / \mathrm{l}$ and $600 \pm 20 \mathrm{mg} / \mathrm{dl})$ compared with mild/asymptomatic COVID-19 (60 $\pm 5 \mu \mathrm{g} / \mathrm{l}, 2 \pm 1 \mu \mathrm{g} / \mathrm{l}$ and $175 \pm 10 \mathrm{mg} / \mathrm{dl})$ and controls $(70 \pm 5 \mu \mathrm{g} / \mathrm{l}, 3 \pm 1 \mu \mathrm{g} / \mathrm{l}$ and

Table 2 Descriptive statistics

\begin{tabular}{|c|c|c|c|}
\hline & Controls, $n=40$ & Mild/asymptomatic, $n=32$ & Moderate, $n=100$ \\
\hline $\mathrm{IL}-6,(<7.0 \mathrm{pg} / \mathrm{ml})$ & $\begin{array}{l}5 \pm 2 \\
\text { Q1 4, Q2 (median) 5, Q3 6, Q4 } 7\end{array}$ & $\begin{array}{l}4 \pm 2 \\
\text { Q1 3, Q2 (median) 4, Q3 5, Q4 } 6\end{array}$ & $\begin{array}{l}54 \pm 12 * \\
\text { Q1 51, Q2 (median) 55, Q3 60, Q4 } 66\end{array}$ \\
\hline TNF- $\alpha(8-10 \mathrm{pg} / \mathrm{ml})$ & $\begin{array}{l}10 \pm 3 \\
\text { Q1 8, Q2 (median) 9, Q3 11, Q4 } 13\end{array}$ & $\begin{array}{l}9 \pm 1 \\
\text { Q1 8, Q2 (median) 9, Q3 9, Q4 } 10\end{array}$ & $\begin{array}{l}45 \pm 5^{*} \\
\mathrm{Q} 143, \mathrm{Q} 2 \text { (median) 46, Q3 48, Q4 } 50\end{array}$ \\
\hline TF $(15.6-1000 \mathrm{pg} / \mathrm{ml})$ & $\begin{array}{l}23 \pm 5 \\
\text { Q1 20, Q2 (median) 24, Q3 26, Q4 } \\
28\end{array}$ & $\begin{array}{l}20 \pm 2 \\
\text { Q1 19, Q2 (median) 20, Q3 21, Q4 } \\
22\end{array}$ & $\begin{array}{l}2000 \pm 500 * \\
\text { Q1 1800, Q2 (median) 2100, Q3 2300, } \\
\text { Q4 2500 }\end{array}$ \\
\hline VWF (50-160\%) & $\begin{array}{l}60 \pm 10 \\
\text { Q1 54, Q2 (median) 61, Q3 65, Q4 } \\
70\end{array}$ & $\begin{array}{l}50 \pm 8 \\
\text { Q1 45, Q2 (median) 50, Q3 53, Q4 } \\
58\end{array}$ & $\begin{array}{l}300 \pm 50 * \\
\text { Q1 270, Q2 (median) 300, Q3 330, } \\
\text { Q4 } 350\end{array}$ \\
\hline TFPI $(75-120 \mathrm{ng} / \mathrm{ml})$ & $\begin{array}{l}81 \pm 12 \\
\text { Q1 77, Q2 (median) 82, Q3 87, Q4 } \\
93\end{array}$ & $\begin{array}{l}75 \pm 10 \\
\text { Q1 71, Q2 (median) 76, Q3 81, Q4 } \\
85\end{array}$ & $\begin{array}{l}166 \pm 69 * \\
\text { Q1 127, Q2 (median) 167, Q3 200, } \\
\text { Q4 } 235\end{array}$ \\
\hline $\mathrm{DD}(50-200 \mu \mathrm{g} / \mathrm{L})$ & $\begin{array}{l}70 \pm 5 \\
\text { Q1 68, Q2 median) 71, Q3 73, Q4 } 75\end{array}$ & $\begin{array}{l}60 \pm 5 \\
\text { Q1 57, Q2 (median) 60, Q3 62, Q4 }\end{array}$ & $\begin{array}{l}550 \pm 100 * \\
\text { Q1 500, Q2 (median) 553, Q3 600, } \\
\text { Q4 } 650\end{array}$ \\
\hline TAT, $(1.0-4.1 \mu \mathrm{g} / \mathrm{L})$ & $\begin{array}{l}3 \pm 1 \\
\text { Q1 2, Q2 (median) 3, Q3 4, Q4 } 4\end{array}$ & $\begin{array}{l}2 \pm 1 \\
\mathrm{Q} 11, \mathrm{Q} 2 \text { (median) 2, Q3 3, Q4 } 3\end{array}$ & $\begin{array}{l}70 \pm 10^{*} \\
\text { Q1 66, Q2 (median) 71, Q3 76, Q4 } 80\end{array}$ \\
\hline Fib (170-400 mg/dL) & $\begin{array}{l}180 \pm 20 \\
\text { Q1 170, Q2 (median) 180, Q3 190, } \\
\text { Q4 } 200\end{array}$ & $\begin{array}{l}175 \pm 10 \\
\text { Q1 170, Q2 (median) } 175 \text { Q3 180, } \\
\text { Q4 } 185\end{array}$ & $\begin{array}{l}600 \pm 20^{*} \\
\text { Q1 } 590, \mathrm{Q} 2 \text { (median) } 600,3610, \mathrm{Q} 4 \\
620\end{array}$ \\
\hline PF4 (1-10 IU/ml) & $\begin{array}{l}4 \pm 1 \\
\text { Q1 3, Q2 (median) 4, Q3 5, Q4 } 5\end{array}$ & $\begin{array}{l}3 \pm 1 \\
\text { Q1 2, Q2 (median) 3, Q3 4, Q4 } 4\end{array}$ & $\begin{array}{l}158 \pm 63 * \\
\text { Q1 125, Q2 (median) 158, Q3 188, } \\
\text { Q4 } 221\end{array}$ \\
\hline$\beta \mathrm{TG}(10-40 \mathrm{IU} / \mathrm{ml})$ & $\begin{array}{l}15 \pm 5 \\
\text { Q1 12, Q2 (median) 15, Q3 17, Q4 } \\
20\end{array}$ & $\begin{array}{l}10 \pm 5 \\
\text { Q1 7, Q2 (median) 10, Q3 12, Q4 } 15\end{array}$ & $\begin{array}{l}245 \pm 20 * \\
\text { Q1 235, Q2 (median) 246, Q3 256, } \\
\text { Q4 } 265\end{array}$ \\
\hline P-Selectin $(18-40 \mathrm{ng} / \mathrm{ml})$ & $\begin{array}{l}20 \pm 10 \\
\text { Q1 15, Q2 (median) 20, Q3 25, Q4 } \\
30\end{array}$ & $\begin{array}{l}30 \pm 10 \\
\text { Q1 25, Q2 (median) 30, Q3 35, Q4 } \\
\quad 40\end{array}$ & $\begin{array}{l}64 \pm 10^{*} \\
\text { Q1 59, Q2 (median) 64, Q3 69, Q4 } 74\end{array}$ \\
\hline
\end{tabular}

*p values: $<0.05$ compared with controls

Table 3 Markers correlations in the moderate COVID group

\begin{tabular}{|c|c|c|c|c|c|c|c|c|c|c|c|}
\hline Markers & IL-6 & TNF- $\alpha$ & $\mathrm{TF}$ & VWF & TFPI & $\mathrm{DD}$ & TAT & FIB & $\beta$-TG & PF4 & P-selectin \\
\hline IL-6 & & & $\mathrm{p}$ & $\mathrm{p}$ & $\mathrm{p}$ & & & & & & \\
\hline TNF- $\alpha$ & & & $\mathrm{p}$ & $\mathrm{p}$ & $\mathrm{p}$ & & & & & & \\
\hline $\mathrm{TF}$ & & & & & & $\mathrm{p}$ & $\mathrm{p}$ & $\mathrm{p}$ & & & \\
\hline VWF & & & & & & $\mathrm{p}$ & $\mathrm{p}$ & $\mathrm{p}$ & & & \\
\hline TFPI & & & & & & $\mathrm{p}$ & $\mathrm{p}$ & $\mathrm{p}$ & & & \\
\hline DD & & & & & & & & & $\mathrm{p}$ & $\mathrm{p}$ & $\mathrm{p}$ \\
\hline TAT & & & & & & & & & $\mathrm{p}$ & $\mathrm{p}$ & $\mathrm{p}$ \\
\hline FIB & & & & & & & & & $\mathrm{p}$ & $\mathrm{p}$ & $\mathrm{p}$ \\
\hline$\beta$-TG & & & & & & $\mathrm{p}$ & $\mathrm{p}$ & $\mathrm{p}$ & & & \\
\hline PF4 & & & & & & $\mathrm{p}$ & $\mathrm{p}$ & $\mathrm{p}$ & & & \\
\hline P-selectin & & & & & & $\mathrm{p}$ & $\mathrm{p}$ & $\mathrm{p}$ & & & \\
\hline
\end{tabular}

$\mathrm{p}$ values $<0.05$ 
$180 \pm 20 \mathrm{mg} / \mathrm{dl}$ ) (Table 2). TF, VWF, and TFPI correlated with DD and TAT and Fib in the moderate COVID group (Table 3). As TFPI can limit coagulation, we measured dPT that was high in moderate COVID-19 $(59 \pm 2 \mathrm{~s})$ compared with mild/asymptomatic COVID-19 ( $25 \pm 5 \mathrm{~s})$ and controls $(20 \pm 3 \mathrm{~s})$. A correlation was found between TFPI and dPT $(\mathrm{p}<0.05)$

\section{The coagulopathy of moderate COVID-19 contributes to platelet activation}

PF4 and $\beta$-TG and P-Selectin were increased in moderate COVID-19 $(158.1 \pm 63 \mathrm{IU} / \mathrm{ml}$ and $245 \pm 20 \mathrm{IU} / \mathrm{ml}$ and $62 \pm 10 \mathrm{ng} / \mathrm{ml}$ ) compared with mild/asymptomatic COVID$19(3 \pm 1 \mathrm{IU} / \mathrm{ml}$ and $10 \pm 5 \mathrm{IU} / \mathrm{ml}$ and $30 \pm 10 \mathrm{ng} / \mathrm{ml})$ and controls $(4 \pm 1 \mathrm{IU} / \mathrm{ml}$ and $15 \pm 5 \mathrm{IU} / \mathrm{ml}$ and $20 \pm 10 \mathrm{ng} / \mathrm{ml})$ (Table 2). PF4 and $\beta$-TG and P-Selectin correlated with DD and TAT and Fib in the moderate COVID group (Table 3 ).

We also found increased platelet adhesion in moderate COVID-19 on C/ADP and C/EPI (C/ADP $48 \pm 10 \mathrm{~s}$ and C/ EPI $42 \pm 5$ s) compared with mild/asymptomatic COVID-19 (C/ADP $70 \pm 10 \mathrm{~s}$ and $90 \pm 10 \mathrm{~s})$ and controls $(75 \pm 15 \mathrm{~s}$ and $100 \pm 20$ s) (Table 4).

\section{The inflammation and endotheliopathy of moderate COVID-19 contribute to whole haemostatic activation}

Shortened CT (CT, unit: s. n.v. 100-240 s) (45 \pm 20 s), shortened CFT (CFT, unit: s, n.v. 30-160 s (15 \pm 10 s), increased MCF (MCF, unit: $\mathrm{mm}$, n.v. $50-72 \mathrm{~mm}(120 \pm 10 \mathrm{~mm})$ and lower LY-30 (LY-30, \%: v.n. 15\% (0.8\%) were in moderate COVID-19 compared with mild/asymptomatic COVID-19 (CT $100 \pm 10 \mathrm{~s}$ and CFT $40 \pm 5 \mathrm{~s}$ and MCF $70 \pm 10 \mathrm{~mm}$ and LY-30 (15\%) and controls (CT $110 \pm 10 \mathrm{~s}$ and CFT $30 \pm 5$ and MCF $60 \pm 10 \mathrm{~mm}$ and LY-30 (15\%) (Table 5).

\section{Discussion}

Thrombosis in COVID-19 is an important part of the clinical picture that needs to be considered [14].

Table 4 PFA-100 parameters of COVID-19 patients and control subjects

\begin{tabular}{lcll}
\hline & Controls, $\mathrm{n}=40$ & $\begin{array}{l}\text { Mild/asympto- } \\
\text { matic, } \mathrm{n}=32\end{array}$ & Moderate, $\mathrm{n}=100$ \\
\hline C/ADP, s & $75 \pm 15$ & $70 \pm 10$ & $48 \pm 10^{*}$ \\
C/EPI, s ${ }^{\mathrm{a}}$ & $100 \pm 20$ & $90 \pm 10$ & $42 \pm 5^{*}$ \\
\hline
\end{tabular}

*p values: $<.05$ compared with controls

${ }^{a}$ Reference values of C(ADP (68-121 s), C/EPI (84-160 s)
Table 5 ROTEM parameters of COVID-19 patients and control subjects

\begin{tabular}{llll}
\hline & Control, $\mathrm{n}=40$ & $\begin{array}{l}\text { Mild/asympto- } \\
\text { matic, } \mathrm{n}=32\end{array}$ & Moderate, $\mathrm{n}=100$ \\
\hline $\mathrm{CT}, \mathrm{s}^{\mathrm{a}}$ & $110 \pm 10$ & $100 \pm 10$ & $45 \pm 20^{*}$ \\
$\mathrm{CFT}, \mathrm{s}^{\mathrm{a}}$ & $30 \pm 5$ & $40 \pm 5$ & $15 \pm 10^{*}$ \\
$\mathrm{MCF}, \mathrm{mm}^{\mathrm{a}}$ & $60 \pm 10$ & $70 \pm 10$ & $120 \pm 10^{*}$ \\
$\mathrm{LY}, \%^{\mathrm{a}}$ & 15 & 15 & $0.8^{*}$ \\
\hline
\end{tabular}

*p values: $<.05$ compared with controls

${ }^{a}$ Reference values of CT (100-240 s), CFT (30-160 s), MCF (50$72 \mathrm{~mm}), \mathrm{LY}(15 \%)$

Histopathologic studies reveal diffuse alveolar damage with profound inflammation and thrombotic microangiopathy of lung vessels [52] and an autopsy series of 11 patients showed thrombosis of small and midsized pulmonary arteries in all patients [53].

Microvascular thrombosis have also been reported in extrapulmonary organs, which may explain the acute onset of multiorgan failure [54]. COVID-19-associated coagulopathy (CAC) is emerged as prominent feature of severe or critically ill patients [55]. It has been reported that COVID-19 is highly thrombotic. Cui et al. [56] reported a $25 \%$ incidence of deep vein thrombosis in patients with severe coronavirus pneumonia in Wuhan [26]. Klok et al. [57] found a $31 \%$ combined incidence of deep vein thrombosis, pulmonary embolism, and arterial thrombosis in critically ill patients with coronavirus [27]. Of these events $81 \%$ were pulmonary thromboemboli.

The hallmark of COVID-19 is a profound inflammation, described as "cytokine storm", characterized by high levels of interleukin-1 (IL-1), IL-6, tumor necrosis factor, and other inflammatory cytokines [37].

Inflammation promotes thrombosis through activation of endothelial cells, platelets, monocytes, and tissue factor, and by altering fibrinolysis and natural anticoagulant pathways (eg, through changes in levels of thrombomodulin, Proteins $\mathrm{C}$ and $\mathrm{S}$, and TFPI) $[58,59]$.

One mechanism of microvascula rthrombosis that may be specific to COVID-19 is the affinity of virus for angiotensin-converting enzyme2, which is expressed on alveolar epithelial type II cells and various extrapulmonary tissues, including endothelial cells. SARS-CoV-2 has been shown to directly invade the endothelial cell [47]. Endothelial cell activation may be a unique mechanism of COVID-19-mediated microvascular injury, thrombosis, and subsequent multi system organ failure and is believed to be a major contributor to coagulopathy, morbidity and mortality [47].

The rate of $87.7 \%$ positivity for lupus anticoagulant in patients with COVID-19 reported by Helmes et al. [60] is striking and needs to be verified, but it supports the idea that 
endothelial injury is a key mechanism of multiorgan failure and coagulopathy in this disease.

The characteristic laboratoriy findings of CAC are significantly elevated levels of D-dimer and fibrinogen, indicating a highly thrombotic state with high fibrin turnover [11]. However, other markers of disseminated intravascular coagulation remain relatively unchanged [42]. The prothrombin time and activated partial thromboplastin time are normal or only mildly prolonged, if at all, and platelet counts are usually normal or marginal reduced [42]. Abnormalities in coagulation parameters have been shown to correlate directly with inflammatory cytokines, severity of illness and adverse outcomes [59].

Many studies have studied the thrombo-inflammatory markers that are associated with the worst prognosis in COVID-19 patients [11] and several reports and metaanalysis have evaluated the link between elevated D-dimer levels and severity and mortality in COVID-19 [41]. Anyway, there is strong criticism about the use of D-dimer test as marker in COVID-19 infection. Infact, it has been reported poor specificity while high levels in clinical conditions other than COVID-19 such as old age, African and American ethnicity, females, malignancies, trauma from surgey, state of pregnancy, physical immobility, drug use, connective tissue inflammation, severe kidney failure, and thromboembolic syndrome [61]. In addition, the D-dimer characterizes an advanced coagulation stage and it results from degradation of clot by fibrinolytic system. The traditional laboratory assays such as PT and APTT are used to measure the plasma coagulation but they do not provide any information about the platelets and the fibrinolysis. In addition, the number of platelets and the fibrinogen levels are fixed parameters that do not give any functional information [61]. Hottz et al. [10] report that activated platelets or products from platelet activation infiltrate to the airways of patients with severe COVID-19. They quantified the levels of TXB2 and the proteins from platelet $\alpha$-granules PF4/ CXCL4 and PDGF in tracheal aspirates from patients with COVID-19 under mechanical ventilation and showed the presence of platelet-derived factors in tracheal aspirates from COVID-19 patients, suggesting that platelet activation and platelet-secretory products gain access to the airways in severe COVID-19 syndrome [10].

As discussed has been reported in severe or critically ill patients with coronavirus. Little attention has been paid to those with mild or moderate infection.

In this study, we show that increased inflammation and hypercoagulability predict moderate COVID-19 patients'poor outcomes, including the requirement of antiviral and eparin therapy and in-hospital admission.
Table 6 COVID-19-associated coagulopathy

Summary of findings

1. Inflammation is manifest as elevated IL- 6 and TNF- $\alpha$

2. Endotheliopathy is manifest as elevated TF, VWF, and TFPI

3. Coagulopathy is manifest as elevated DD, TAT, and Fib

4. Platelet activation is manifest as elevated PF4 and $\beta$ TG

5. IL-6 and TNF- $\alpha$ levels are correlated with TF, VWF, and TFPI

6. TF, VWF, and TFPI levels are correlated with DD, TAT, and Fib

7. DD, TAT, and Fib levels are correlated with PF4 and $\beta$ TG

8. Whole blood viscoelastic analysis sustains the coagulopathy

9. Coagulopathy appears to be related to inflammation and endotheliopathy and not intrinsic viral activity

Our data show profound inflammation and endoteliopathy that confer coagulation activation and platelet activation in moderate COVID-19 patients compared with mild COVID-19 patients. First, we measured IL- 6 and TNF- $\alpha$ levels that reflect a higher inflammatory state in moderate COVID-19 patients than mild COVID-19 patients. Second, TF and VWF are released by activated and damaged endothelium, which likely occurs early in COVID-19. Of note, our plasma very high TFPI levels measured later in the disease process during hospitalization did not attenuate inflammation and coagulation. Third, plasma D-dimer, TAT and Fg originated from thrombin-activated fibrinolysis positively correlated with TF, VWF and TFPI reflecting a endothelial hypercoagulability state (see Table 6).

There are data consistent with the notion that intense cytokine production may trigger hyperinflammation and haemostatic hypercoagulability [62]. Proinflammatory cytokines and procoagulant factors such as thrombin may also contribute to TF expression in monocytes [63]. We show that the proinflammatory cytokines and TAT may contribute to TF expression in our cohort of moderate COVID-19.

Four, increased platelet activation is observed in moderate COVID-19 patients, but not in patients presenting mild COVID-19 infection. The mechanisms underlying platelet activation in COVID-19 remain unknown. New studies are still necessary to better characterize the platelet activation in COVID-19. Platelets are anucleate blood cells classically known by their roles in haemostasis and patological thrombosis [10]. Haemostatic activities involve platelet aggregation and thrombus formation, platelets also coordinate vascular function and integrity by complex interactions with endothelial cells and leukocytes [10]. Activated platelets reprogram cellular functions of adjacent cells by heterotypic cellular interactions and juxtacrine signals from P-selectin 
and integrins [10]. Platelets modulate critical leukocyte responses such as migration, secretion, extrusion of neutrophil extracellular traps, recruitment to growing thrombi, and monocyte expression of $\mathrm{TF}^{-}$an essential trigger of coagulation and thrombosis [10]. Our data show a correlation between inflammatory cytokines and platelet-secretory products suggesting that the inflammation confers platelet activation. Platelets are also known to modulate secretion of cytokines [10]. It has been shown that during viral infections, including dengue, HIV, and influenza, platelets change the monocyte cytokine profile toward a proinflammatory pattern [10]. In this study has been showed that during moderate COVID-19 infection activated platelets change the systemic cytokine profile toward a proinflammatory pattern, amplifying inflammation. Platelet hyperaggregation was assessed on COVID-19 patients who were not on aspirin or other antiplatelet agents [64]. Platelet hyperadhesion was assessed in our moderate COVID-19 patients on $\mathrm{C} / \mathrm{ADP}$ in according to a recent report that report ADP as a key player in the development of microvascular thrombosis in COVID-19 patients [64]. Aspirin pretreatment of platelets from SARS-CoV-2-infected patients abolishes this hyperactivity [64]. Our findings of platelet activation further suggest that antiplatelet therapy may be warranted in treating COVID-19 patients.

In this study, each of these molecular events and cellular interactions were studied by thromboelastometry to confirm the CAC and to guide therapy.

Whole haemostatic system is easily analysed by use of thromboelastography (TEG) or rotational thromboelastometry (ROTEM), able to measure the haemostasis from the formation of the clot to its dissolution [61].

Several reports have been published describing early experience with TEG or ROTEM for patients admitted with severe or critical disease in Italy and the United States [61]. However, information on viscoelastic testing among patients with moderate COVID-19 is scarce.

Maatman et al. [65] and Wright et al. [66] reported the presence of hypercoagulability in COVID-19 by use of TEG and hypofibrinolysis. In according to these data, we noted that CT and CFT were shortened and MCF high and clot lysis at $30 \mathrm{~min}$ (LY-30) was low in 100\% in our cohort of patients with moderate COVID-19.

In summary, our study supports moderate COVID-19 infection as a hypercoagulable and hypofibrinolytic state (Table 5). By easy test execution and its property to measure all factors involved in haemostatic system and stages of coagulation process and platelet function in the sick bed, thromboelametry might be suited to evaluate the thrombosis risk in patients with COVID-19.

In line with these results and in according to FDA Issues Guidance for Measuring Viscoelasticity Amid COVID19 Pandemic (FDA.gov, January 28, 2021), we suggest to routinely use the whole blood viscoelastic analysis that measures the whole blood capability to make and sustain clot formation in hospitalized COVID-19 patients for the purpose of identifying the individual patient's degree of thrombotic risk. In this study the associations of menu of markers were correlated with PE suggesting the possibility to identify a specific patient population for which specific management options may be selected. Given that none of the markers are considered or recommended by societies for routine management and given that it seems highly unlikely that each test or measure would or needs to be performed in clinical practice, the clinician will interpret these results as probable harbingers of hypercoagulability and the data may suggest that one or more is sufficient for prognostic purposes.

Author contributions RC, EGC, VV, and EC equally contributed to the writing of this manuscript.

\section{Declarations}

Conflict of interest The authors declare no competing financial interests.

\section{References}

1. Liao D, Zhou F, Luo L et al (2020) Haematological characteristics and risk factors in the classification and prognosis evaluation of COVID-19: a retrospective cohort study. Lancet Haematol 7:e671-678

2. Layton DS, Chudhary A, Bean AGD (2017) Breaking the chain of zoonoses through biosecurity in livestock. Vaccine 35(44):59675973 (eliminare)

3. Middeldorp S, Coppens M, van Haaps TF et al (2020) Incidence of venous thromboembolism in hospitalized patients with COVID-19. J Thromb Haemost 18(8):1995-2002

4. Cattaneo M, Bertinato EM, Birocchi S et al (2020) Pulmonary embolism or pulmonary thrombosis in COVID-19? Is the recommendation to use high-dose heparin for thromboprophylaxis justified? Thromb Haemost 120:1230-1232

5. Danzi GB, Loffi M, Galeazzi G et al (2020) Acute pulmonary embolism and COVID-19 pneumonia: a random association? Eur Heart J 41(19): 1858

6. Rotzinger DC, Beigelman-Aubry C, von Garnier C et al (2020) Pulmonary embolism in patients with COVID-19: time to change the paradigm of computed tomography. Thromb Res 190:58-59

7. Fox SE, Akmatbekov A, Harbert JL et al (2020) Pulmonary and cardiac pathology in African American patients with COVID10: an autopsy series from New Orleans. Lancet Respir Med 8(7):681-686 (published online ahead of print 27 May 2020)

8. Du Y, Tu L, Zhu P et al (2020) Clinical features of 85 fatal cases of COVID-19 from Wuhan: a retrospective observational study. Am J Respir Crit Care Med 201(11):1372-1379

9. Middleton EA, HE X-Y, Denorme F et al (2020) Neutrophil extracellular traps contribute to immunothrombosis in COVID-19 acute respiratory distress syndrome. Blood 136(10):1169-1179 
10. Hottz ED, Azevedo-Quintanilha IG, Palhinha L et al (2020) Platelet activation and platelet-monocyte aggregate formation trigger tissue factor expression in patients with severe COVOD-19. Blood 136(11):1330-1341

11. Tang N, Li D, Wang X et al (2020) Abnormal coagulation parameters are associated with poor prognosis in patients with novel coronavirus pneumonia. J Thromb Haemost 18(4):844-847

12. Giamarellos-Bourboulis EJ, Netea MG, Rovina N et al (2020) Complex immune dysregulation in COVID-19 patients with severe respiratory failure. Cell Host Microbe 27(6):992-1000. e3

13. Zhou F, Yu T, Du R et al (2020) Clinical course and risk factors for mortality of adult in patients with COVID-19 in Wuhan, China: a restrospective cohort study. Lancet 395(10229):1054-1062

14. Connors JM, Levy JH (2020) COVID-19 and its implications for thrombosis and anticaogulation. Blood 135(23):2033-2040

15. Engelmann B, Massberg S (2013) Thrombosi as an intravascular effector of innate immunity. Nat Rev Immnunol 13(1):34-45

16. Delabranche X, Helms J, Meziani F (2017) Immunohaemostasis: a new view on haemostasis during sepsis. Ann Intensive Care 7(1):117

17. Jackson SP, Darbousset R, Schoenwaelder SM (2019) Thromboinflammation: challenges of therapeutically targeting coagulation and other host defense mechanisms. Blood 133(9):906-918

18. Woei-A-Jin FJ, van der Starre WE, Tesselaar ME et al (2014) Procoagulant tissue factor activity on microparticles is associated with disease severity and bacteremia in febrile urinary tract infections. Thromb Res 133(5):799-803

19. Gould TJ, Lysov Z, Swystun LL et al (2016) Canadian critical care translational biology group extracellular histones increase tissue factor activity and enhance thrombi generation by human blood monocytes. Shock 46(6):655-662

20. Iba T, Levy JH (2018) Inflammation and thrombosis: roles of neutrophils, platelets, and endothelial cells and their interactions in thrombus formation during sepsis. J Thromb Haemost 16(2):231-241

21. Peter L, Giesen A, Rauch U et al (1999) Blood-borne tissue factor: Another view of thrombosis. Proc Natl Acad Sci USA 96:2311-2315

22. Esmon CT (2003) Inflammation and thrombosis. J Thromb Haemost 1:1343-1348

23. Bar-Shavit R, Kahn AJ, Mann KG et al (1986) Identifiaction of a thrombin sequence with growth factor activity in on macrophages. Proc Natl Acad Sci USA 83:976-980

24. Lorant DE, Patel KD, McIntyre TM et al (1991) Coexpression of GMP-140 and PAF by endothelium stimulated by histamine or thrombin: a juxtacrine system for adhesion and activation of neutrophils. J Cell Biol 115:223-234

25. Pendurthi UR, Alok D, Rao LVM (1997) Binding of factor VIIa to tissue factor induces altetations in gene expression in human fibroblast cells: upregulation of poly (A) polymerase. Proc Natl Acad Sci USA 94:2598-2603

26. Miller DL, Yaron R, Yellin MJ (1998) CD40L-CD40 interactions regulate endothelial cell surface tissue factor and thrombomodulin expression. J Leukoc Biol 63:373-379

27. Andrè P, Srinivasa Prasad KS, Denis CV et al (2002) CD40L stabilizes arterial thrombi by a $\beta 3$ integrin-dependent mechanism. Nat Med 8:247-252

28. Henn V, Slupsky JR, Grafe M et al (1998) CD40 ligand on activated platelets triggers an inflammatory reaction of endothelial cells. Nature 391:591-594

29. Burstein SA (1997) Cytokines, platelet productions and hemostasis. Platelets 8:93-104

30. Taylor FB, Chang A, Esmon CT et al (1987) Protein C prevents the coagulopathic and lethal effects of $E$. coli infusion in the baboon. J Clin Investig 79:918-925
31. Lupu C, Lupu F, Dennechy U et al (1995) Thrombin induces the redistribution and acute release of tissue factor pathway inhibitor from specific granules within human endothelial cells in culture. Arterioscler Thromb Vasc Biol 15:2055-2062

32. Goldfarb RD, Glock D, Johnson K et al (1998) Randomized, blinded, placebo-controlled trial of tissue factor pathway inhibitor in porcine septic shock. Shock 10(4):258-264

33. Matyal R, Vin Y, Delude RL et al (2001) Extremely low doses of tissue factor pathway inhibitor decrease mortality in a rabbit model of septic shock. Intensive Care Med 27(8):1274-1280

34. Creasey AA, Chang AC, Feigen L et al (1993) Tissue factor pathway inhibitor reduces mortality from Escherichia Coli septic shock. J Clin Investig 91(6):2850-2860

35. de Jonge E, Dekkers PE, Creasey AA et al (2000) Tissue factor pathaway inhibitor dose-dependently inhibits coagulation activation without influencing the fibrinolytic and cytokine response during human endotoxemia. Blood 95(4):1124-1129

36. Abraham E, Reinhart K, Svoboda P et al (2001) Assessment of the safety of recombinant tissue factor pathway inhibitor in patients with severe sepsis: a multicenter, rabdomized, placebocontrolled, single-blind, dose escalation study. Crit Care Med 29(11):2081-2089

37. Huang C, Wang Y, Li X et al (2020) Clinical features of patients infected with 2019 novel coronavirus in Wuhan. China Lancet 395(10223):497-506

38. Iba T, Levy JH, Warkentin TE, Thachil J et al (2019) Scientific and standardization committee on DIC, and the scientific and standardization committee on perioperative and clinical care of the international society of thrombosis and haemostasis. Diagnosis and management of sepsi-induced coagulopathy and disseminated intravascular coagulation. J Thromb Haemost 17(11):1989-1994

39. Taylor FB, Toh CH, Hoots WK et al (2001) Subcommittee on disseminated intravascular coagulation (DIC) of the international society on thrombosis and haemostasis (ISTH). Towards definition, clinical and laboratory criteria, and a scoring system for disseminated intravascular coagulation. Thromb Haemost 86(5): 1327-1330

40. Iba T, Levy JH, Yamakawa K et al (2019) Scientific and standadization committee on DIC of the international society on thrombosis and haemostasis. Proposal of a two-step process for the diagnosis of sepsis-induced disseminated intravascular coagulation. J Thromb Haemost 17(8):1265-1268

41. Tang N, Bai H, Chen X et al (2020) Anticoagulant treatmemt is associated with decreased mortality in severe coronavirus disease 2019 patients with coagulopathy. J Thromb Haemost 18(5):1094-1099

42. Siegal DM, Barnes GD, Langlois NL et al (2020) A toolkit for the collection of thrombosis-related data elements in COVID-19 clinical studies. Blood Adv 4(24):6259-6273

43. Suzuki K, Wada H, Imai H et al (2018) Subcommittee on disseminated intravascular coagulation. A re-evaluation of the D-dimer cut-off value for making a diagnosis according to the ISTH overtDIC diagnostic criteria: communication from the SSC of the ISTH. J Thromb Haemost 16(7):1442-1444

44. Schnittler HJ, Feldmann H (2003) Viral hemorrhagic fever-a vascular disease? Thromb Haemost 89(6):967-972

45. Rittirsch D, Flierl MA, Ward PA (2008) Harmful molecular mechanisms in sepsis. Nat Rev Immunol 8(10):776-787

46. Iba T, Levy JH (2019) Derangement of the endothelial glycolalyx in sepsis. J Thromb Haemost 17(2):283-294

47. Varga Z, Flammer AJ, Steiger P et al (2020) Endothelial cell infection and endothelitis in COVID-19. Lancet. https://doi.org/ 10.1016/S0140-6736(20)30937-5 (published online ahead of print 20 April 2020) 
48. Iba T, Levy JH, Thachil J et al (2019) Scientific and standardization committee on DIC of the international society on thrombosis and haemosatsis. The progression from coagulopathy to disseminated intravsacular coagulation in representative undelying diseases. Thromb Res 179:11-4. (n. 51)

49. Iba T, Levy JH, Wada $\mathrm{H}$ et al (2019) Subcommittee on disseminated intravascular coagulation. Differential diagnoses for sepsisinduced disseminated intravascular coagulation: communication from the SSC of the ISTH. J Thromb Haemost 17(2):415-419

50. Ranucci M, Ballotta A, Di Dedda U et al (2020) The procoagulant pattern of patients with COVID-19 acute respiratory distress syndrome. J Thromb Haemost. https://doi.org/10.1111/jth.14854

51. National Health Commission, National Administration of Traditional Chinese Medicine (2020) Diagnosis and treatment protocol for novel coronavirus pneumonia (trial version 7). Chin Med J 133:1087-1095

52. Fox SE, Akmatbekov A, Harbert JL et al (2020) Pulmonary and cardiac pathology in COVID-19: the first autpsy series from New Orleans. MedRxiv 22:1-358

53. Lax SF, Skok K, Zechner P et al (2020) Pulmonary arterial thrombosis in COVID-19 with fatal outcome: results from a prospective, single-center, clinicopathologic case series. Ann Intern Med 14:M20-2566

54. Zhang T, Sun LX, Feng RE (2020) Comparison of clinical and pathological features between severe acute respiratory syndrome and coronavirus disease 2019. Zhonghua Jie $\mathrm{He} \mathrm{He} \mathrm{Hu} \mathrm{Xi} \mathrm{Za} \mathrm{Zhi}$ 43(6):496-502 (Chinese)

55. Mucha SR, Dugar S, McCrae K et al (2021) Update to coagulopathy in COVID-19: manifestations and management. Clevel Clin J Med. https://doi.org/10.3949/ccjm.87a.ccc024-up

56. Cui S, Chen S, Li X et al (2020) Prevalence of venous thromboembolism in patients with severe novel coronavirus pneumonia. $\mathrm{J}$ Thromb Haemost 18(6):1421-1424

57. Klok FA, Kruip MJ, van der Meer NJ et al (2020) Incidence of thrombotic complications in critically ill ICU patients with COVID-19. Thromb Res 191:145-147

58. Levi M, Scully M (2018) How I treat disseminated intravscular coagulation. Blood 131(8):845-854

59. Liu Y, Gao W, Guo W et al (2020) Prominent coagulation disorder is closely related to inflammatory response and could be as a prognostic indicator for ICU patients with COVID-19. J Thromb Thrombolysis 50(4):825-832

60. Helms J, Tacquard D, Severac F et al (2020) High risk of thrombosis in patients in severe SARS-CoV-2 infection: a multicenter prospective cohort study. Intensive Care Med 46(6):1089-1098

61. Chaudhary R, Kreutz RP, Bliden KP et al (2020) Personalizing antithrombotic therapy in COVID-19: role of thromboelastography and thromboelastometry. Thromb Haemost 120:1594-1596

62. Jose RJ, Manuel A (2020) COVID-19 cytokine storm: the interplay between inflammation and coagulation. Lancet Respir Med 8(6):e46-e47

63. Schechter ME, Andrade BB, He T et al (2017) Inflammatory monocytes expressing tissue factor drive SIV and HIV coagulopathy. Sci Transl Med 9(405):5441

64. Manne BK, Denorme F, Middleton EA et al (2020) Platelet gene expression and function in patients with COVID-19. Blood 136(11):1317-1329

65. Maatman TK, Jalali F, Feizpour C et al (2019) Routine venous thromboembolism prophylaxis may be inadequate in the hypercoagulable state of severe coronavirus disease. Crit Care Med. https://doi.org/10.1097/CCM.0000000000004466

66. Wright FL, Vogler TO, Moore EE et al (2020) Fibrinolysis shutdown correlation with thromboembolic events in severe COVID19 infection. J Am Coll Surg 231(2):193-203

Publisher's Note Springer Nature remains neutral with regard to jurisdictional claims in published maps and institutional affiliations. 